\title{
THE RELIABILITY OF MEASURES PROVIDED BY THE UNSTABLE PLATFORM FOR BALANCE ANALYSIS IN YOUNG ADULTS WITH AND WITHOUT VISUAL INFORMATION
}

original paper

(c) Wroclaw University of Health and Sport Sciences

DOI: https://doi.org/10.5114/hm.2022.107978

\section{JULIANE CRISTINA LEME ${ }^{1,2,3 \oplus}$, CRISTIANE REGINA COELHO CANDIDO ${ }^{1,2}{ }^{\circledR}$, VITOR BERTOLI NASCIMENTO ${ }^{1,2}{ }^{1}$, JULIANA BAYEUX DASCAL ${ }^{1,2}$, VICTOR HUGO ALVES OKAZAKI ${ }^{1,2,3 \odot}$}

\author{
${ }^{1}$ Motor Neuroscience Laboratory Research Group, State University of Londrina, Londrina, Brazil \\ ${ }^{2}$ Laboratory of Teaching and Research in Biomechanics, State University of Londrina, Londrina, Brazil \\ ${ }^{3}$ Tutorial Educational Program of Physical Education, State University of Londrina, Londrina, Brazil
}

\begin{abstract}
Purpose. The Unstable Platform for Balance Analysis (UP-balance) has been used in several studies to evaluate different situations of balance and constraints. However, the reliability of its measurements has not been analysed yet. Therefore, the present study investigated the reliability of the measures provided by UP-balance in young adults in bipedal posture with and without vision.

Methods. For such analysis, 30 young adults, male and female (mean age: 22.9 years; $S D=3.8$ years), performed 3 attempts of the task which consisted in maintaining balance on an UP-balance on a bipedal base for 20 seconds, with and without visual information, with perturbations in the medial-lateral and anterior-posterior directions.

Results. The UP-balance variables presented high inter-trial reliability (ICC $>0.76$; $p<0.05$ ), except for balance time in the anterior-posterior direction and non-vision condition, which exhibited moderate inter-trial reliability (ICC $=0.73 ; p<0.05)$. Conclusions. UP-balance seemed to be a reliable instrument for the analysis of balance in situations of instability on a base support.
\end{abstract}

Key words: postural control, dynamic balance, instability, instrument

\section{Introduction}

Postural balance corresponds to the state in which all forces acting on the body are balanced, allowing to maintain or control body mass centre projection within the limits of the supporting base [1, 2]. Dynamic balance is used to maintain posture during controlled movements (unstable situations), while in orthostatic balance (stable/static situations) the maintenance of the desired position and orientation occurs [1]. Force and pressure platforms are the most frequently used instruments for these analyses [3].

Balance tests performed on force platforms have shown that the body sway is greater in elderly than in younger adults [4]; they are predictive of survival among older people [5]. Also, poor results in these tests are associated with difficulties in activities of daily living [6]. Finally, a systematic review showed that some force platform parameters could provide valuable information in predicting future falls and recurrent fallers [7]. However, it has been noted that the greater part of the balance analysis was performed in quiet orthostatic situations. Meanwhile, in most cases, falls are reported in situations of instability (dynamic situations) [8].

Dynamic situations on a force platform have been investigated through the use of disturbance in order to analyse the strategies of stability maintenance or recovery. For example, balance can be investigated in environments that simulate moveable rooms $[9,10]$,

Correspondence address: Juliane Cristina Leme, Universidade Estadual de Londrina, Centro de Educação Física e Esporte, Campus Universitário - Rodovia Celso Garcia Cid km 380, cep: 86057-970, Londrina, Paraná, Brazil, e-mail: jucris.leme@gmail.com, https://orcid.org/0000-0003-2906-7850

Received: June 19, 2020

Accepted for publication: February 17, 2021

Citation: Leme JC, Candido CRC, Nascimento VB, Dascal JB, Okazaki VHA. The reliability of measures provided by the Unstable Platform for Balance Analysis in young adults with and without visual information. Hum Mov. 2022;23(3):104-112; doi: https://doi.org/10.5114/hm.2022.107978. 
scenes with movement [11], lifting unpredictable loads [12], and a support base of unstable material [9, 13]. Even considering the contributions of these designs with a stable force platform, the instability provided by movement on a support base has received special attention [14] because it seems more ecological compared with fall situations [15].

Dynamic balance analysis can be performed with different protocols. Among the more frequently used and well-known functional tests to evaluate dynamic balance are the Star Excursion Balance Test and Y-Balance Test [16]. These tests provide a valid and reliable measure of dynamic balance $[17,18]$, especially when variables such as anthropometric characteristics, sex, and lower limb strength are controlled [19]. Instruments such as Both Sides Up [20], balance board [21], wobble boards [22], Clever Balance Board [23], and NeuroCom $[24,25]$ have also been used for training and to assess balance in situations of instability. Some of these devices had their reliability assessed in young adults. In general, moderate to high reliability of balance measures in dynamic situations has been demonstrated $[17,18,22-25]$. Therefore, portable, easy, and low-cost tools are needed to evaluate dynamic balance.

The Unstable Platform for Balance Analysis (UPbalance) [26] has been an alternative for the dynamic balance evaluation. This instrument may be built at a low cost because it is a simple structure made of wood supported by a semi-circular base, with 2 sensors attached to its side borders. The sensors are connected to a computer, and specific software provides the measures of balance time (BT) and the number of imbalances (number of touches [NT] of the sensors on the ground) in situations of instability in the medial-lateral (ml) and anterior-posterior (ap) directions.

UP-balance has been employed in studies to analyse the impact of visual occlusion [27], to compare the dynamic balance of individuals with Down syndrome and those with typical development [28], to investigate the effect of focusing attention during unstable balance tasks [29], to compare balance in classical ballet practitioners, ballroom dancers, and non-practitioners of dance [30], and to compare the influence of visual occlusion and light touch between elderly people and young adults [27]. However, despite previous studies with UP-balance, the reliability of its measurements has not been analysed yet.

This study aimed to verify the reliability of the measures of UP-balance in young adults with and without vision and with perturbation of the basis of support in the $\mathrm{ml}$ and ap directions. It was hypothesized that all the variables provided by UP-balance would present high or moderate reliability. This research might deliver evidence for the use of UP-balance as a reliable tool in the analysis of dynamic balance.

\section{Material and methods}

\section{Participants}

The study involved 30 young adults (20 men, 10 women), selected by convenience, with a mean age of 22.9 years $(S D=3.8)$, mean height of $1.72 \mathrm{~m}(S D=0.10)$, mean weight of $71.3 \mathrm{~kg}(S D=12.6)$, and body mass index of $23.98 \mathrm{~kg} / \mathrm{m}^{2}(S D=3.13)$. In accordance with the short form International Physical Activity Questionnaire (IPAQ) [31], the distribution of participants regarding physical activity was: 11 individuals with moderate physical activity and 19 individuals with high physical activity. The participants reported verbally that they were not under medication that could affect their balance and that they had no previous injury (within up to 6 months before the test) that could affect their balance.

\section{Experimental procedures}

First, the participants signed the free and informed consent. Then, they completed the short form IPAQ, which allowed to characterize their physical activity [31]. The weight and height measurements were implemented by using a Wiso (Wiso, São José, Brazil) (W721) digital weighing device and a Wiso (Wiso, São José, Brazil) (E210) compact stadiometer.

UP-balance [26] is composed of a wooden plank $(40 \times 40 \mathrm{~cm}) 1.5 \mathrm{~cm}$ high, with electronic sensors coupled on its side borders, responsible for capturing moments when the border touches the ground; it is supported by a semicircle wooden base $4.4 \mathrm{~cm}$ high, 2.4 $\mathrm{cm}$ wide, and $2.2 \mathrm{~cm}$ in radius. The variables of UP-balance were sent through an analogue-digital adapter (v. 1.5) for the Dynamic Balance Task software (v. 1.0) to an Acer (4349-ZQR) laptop (Figure 1A).

The participants performed a dynamic balance task on the UP-balance in 4 different conditions of disturbance: $1^{\text {st }}$ condition $-\mathrm{ml}$, with vision $(\mathrm{V}) ; 2^{\text {nd }}$ condition - ml, non-vision (NV); $3^{\text {rd }}$ condition - ap and V; $4^{\text {th }}$ condition - ap and NV. The order of conditions was randomized among the individuals. The participants were instructed to remain on the UP-balance for 20 seconds avoiding the border touching the ground. They began behind the UP-balance and, after authorization from 


\section{HUMAN MOVEMENT}

J.C. Leme et al., Reliability of UP-balance measures
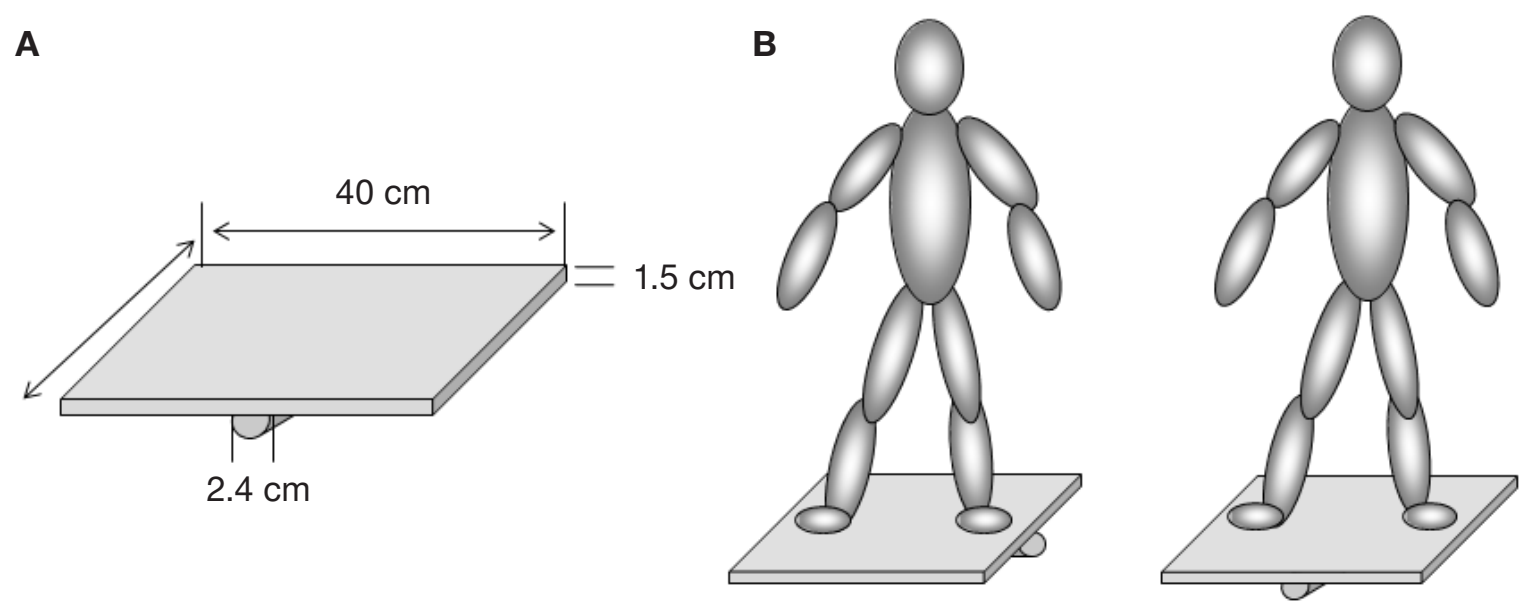

Figure 1. Schematic representation of (A) the UP-balance and (B) the balance tasks with ap perturbation and with ml perturbation

the experimenter, they were instructed to step onto the platform keeping the right side supported on the ground in the $\mathrm{ml}$ direction of disturbance or the back supported in the ap direction, depending on the condition selected at randomization. The balance task was performed by the participants barefoot, with a bipedal base of support, with the arms extended alongside the body. The feet were positioned parallel to each other, separated approximately shoulder-width apart, and the knees were slightly flexed (Figure 1B).

In the $\mathrm{V}$ conditions, the participants were instructed to look at a fixed point marked on the wall $(1.80 \mathrm{~m}$ distance from the participants, at the height of their eyes). In the NV conditions, a blindfold was used. The individuals were asked to maintain the position of the head imagining that they were looking at the fixed point ahead. There was one familiarization trial for each task condition. Next, 3 trials were performed for each task condition, with a 30-second interval between trials. These procedures are in accordance with previous research [27-30].

\section{Variables and statistical analysis}

The independent variables were: UP-balance support base $(\mathrm{ml} \times \mathrm{ap})$ and visual condition $(\mathrm{V} \times \mathrm{NV})$. The dependent variables were: (a) BT in seconds, which represented the sum of the times in which each participant remained on the platform without the border touching the ground; and (b) the number of imbalances in absolute frequency (af), which represented the total NT of the platform border on the ground. Initially, the average of the 3 trials for each measure of balance for all conditions was calculated. The inter- trial reliability for each condition was determined by calculating the intraclass correlation coefficient (ICC) [32] with its 95\% confidence interval (CI). A 2-way random-effect model was used to assess inter-trial reliability $\left(\mathrm{ICC}_{2,1}\right)$ [33]. Furthermore, the standard error of measurement (SEM) and the minimal detectable change (MDC) were determined. SEM was estimated with the following formula:

$$
\mathrm{SEM}=S D \times \sqrt{(1-r)}
$$

where $S D$ is the standard deviation of the measure, and $r$ is the ICC value. MDC was calculated by using the formula:

$$
\mathrm{MDC}=\mathrm{SEM} \times 1.96 \times \sqrt{2}
$$

Statistical analyses were performed with the SPSS software (v. 18), with significance established at 5\% $(p<0.05)$.

\section{Ethical approval}

The research related to human use has complied with all the relevant national regulations and institutional policies, has followed the tenets of the Declaration of Helsinki, and has been approved by the State University of Londrina ethics committee (Report No. 1.336.512, CAAE No. 50124115.4.0000.5231).

\section{Informed consent}

Informed consent has been obtained from all individuals included in this study. 


\section{Results}

The mean of the 3 trials at each measure of balance for all conditions was presented in Table 1. ICC, 95\% CI, SEM, and MDC values are depicted in Table 2. For visualization of the relationships, scatterplots are provided for $\mathrm{BT}$ variables in the $\mathrm{V}$ and $\mathrm{NV}$ conditions (Figure 2) and for NT variables in the V and NV conditions (Figure 3).

The $\mathrm{BTml}$ reliability in the $\mathrm{V}$ condition $\left(\mathrm{ICC}_{2,1}=\right.$ $0.89, \mathrm{SEM}=0.52 \mathrm{~s}$ ) was better than BTml in the NV condition $\left(\mathrm{ICC}_{2,1}=0.76, \mathrm{SEM}=0.70 \mathrm{~s}\right)$. MDC was also better (smaller) for BTml in the $\mathrm{V}$ condition $(1.45 \mathrm{~s})$ than for BTml in the NV condition (1.96 s). Also, better reliability was presented in BTap in the $\mathrm{V}$ condition $\left(\mathrm{ICC}_{2,1}=0.77, \mathrm{SEM}=0.60 \mathrm{~s}\right)$ than in BTap in the NV condition $\left(\mathrm{ICC}_{2,1}=0.73, \mathrm{SEM}=0.65 \mathrm{~s}\right)$. MDC for BTap in the $\mathrm{V}$ condition $(1.67 \mathrm{~s}$ ) was better than in the $\mathrm{NV}$ condition (1.81 s).

The $\mathrm{NTml}$ reliability in the $\mathrm{NV}$ condition $\left(\mathrm{ICC}_{2,1}=\right.$ $0.84, \mathrm{SEM}=2.14 \mathrm{af}$ ) was better than in the $\mathrm{V}$ condition $\left(\mathrm{ICC}_{2,1}=0.82, \mathrm{SEM}=2.15 \mathrm{af}\right)$. MDC was also better (smaller) for NTml in the NV condition (5.95 af) than for NTml in the V condition (5.96 af). Also, better reliability was presented in NTap in the NV condition

Table 1. Descriptive data of the UP-balance variables

\begin{tabular}{lcccc}
\hline \multirow{2}{*}{ Variables } & \multicolumn{2}{c}{ V } & \multicolumn{2}{c}{ NV } \\
\cline { 2 - 5 } & Mean & $S D$ & Mean & $S D$ \\
\hline BTml (s) & 13.19 & 1.58 & 11.50 & 1.44 \\
BTap (s) & 12.03 & 1.26 & 9.94 & 1.26 \\
NTml (af) & 23.07 & 5.07 & 24.13 & 5.37 \\
NTap (af) & 26.31 & 6.06 & 27.79 & 6.80 \\
\hline
\end{tabular}

$\mathrm{V}$ - with vision, NV - non-vision, BT - balance time, NT - number of touches of the platform border on the ground, $\mathrm{ml}$ - medial-lateral direction, ap - anterior-posterior direction, af - absolute frequency
$\left(\mathrm{ICC}_{2,1}=0.89, \mathrm{SEM}=2.25 \mathrm{af}\right)$ than in the $\mathrm{V}$ condition $\left(\mathrm{ICC}_{2,1}=0.81, \mathrm{SEM}=2.64 \mathrm{af}\right) . \mathrm{MDC}$ for NTap in the $\mathrm{NV}$ condition ( $6.25 \mathrm{af}$ ) was better than in the $\mathrm{V}$ condition (7.32 af).

All UP-balance variables presented high inter-trial reliability, except for BTap in the NV condition, which demonstrated moderate inter-trial reliability $(p<0.05)$.

\section{Discussion}

The present study analysed the reliability of the measures of UP-balance among young adults in the $\mathrm{V}$ and NV conditions, with perturbation of the basis of support in the $\mathrm{ml}$ and ap directions. In general, the results showed that UP-balance exhibited high reliability for all variables in the $\mathrm{V}$ and $\mathrm{NV}$ conditions, except for the BTap variable in the NV condition: in this case, moderate reliability was observed. Therefore, the hypothesis that the variables of UP-balance would provide reliability was confirmed.

The study presented greater reliability in the NV than in the $\mathrm{V}$ condition in the NT variable ( $\mathrm{ml}$ and ap). Previous research verified the reliability of data of a force platform in young adults and the elderly $[34,35]$. The results demonstrated higher reliability values for most measures in the NV conditions in comparison with the $\mathrm{V}$ conditions in both studies. It was suggested that NV was a condition unfamiliar to most participants. Since vision is an important source of postural control, it was proposed that it was probably easier for the individuals to adapt in the $\mathrm{V}$ than in the NV conditions [34, 35].

Our results corroborate these studies because it seems that during the NV condition, the participants were unable to change the control of movement to maintain balance, probably owing to the lack of information provided by the visual system on the relative position and movement of the body parts and of the body

Table 2. ICC, 95\% CI, SEM, and MDC values for the UP-balance variables

\begin{tabular}{|c|c|c|c|c|c|c|c|c|}
\hline \multirow{2}{*}{ Variables } & \multicolumn{4}{|c|}{ V } & \multicolumn{4}{|c|}{$\mathrm{NV}$} \\
\hline & ICC & $95 \%$ CI & SEM & MDC & ICC & $95 \% \mathrm{CI}$ & SEM & MDC \\
\hline BTml (s) & $0.89 *$ & $0.80-0.94$ & 0.52 & 1.45 & $0.76^{*}$ & $0.57-0.88$ & 0.70 & 1.96 \\
\hline ВТар (s) & $0.77^{*}$ & $0.59-0.88$ & 0.60 & 1.67 & $0.73^{*}$ & $0.49-0.86$ & 0.65 & 1.81 \\
\hline NTml (af) & $0.82 *$ & $0.66-0.91$ & 2.15 & 5.96 & $0.84^{*}$ & $0.71-0.92$ & 2.14 & 5.95 \\
\hline NTap (af) & $0.81 *$ & $0.66-0.90$ & 2.64 & 7.32 & $0.89^{*}$ & $0.80-0.94$ & 2.25 & 6.25 \\
\hline
\end{tabular}

$\mathrm{V}$ - with vision, NV - non-vision, ICC - intraclass correlation coefficient, CI - confidence interval, SEM - standard error of measurement, MDC - minimal detectable change, BT - balance time, NT - number of touches of the platform border on the ground, $\mathrm{ml}$ - medial-lateral direction, ap - anterior-posterior direction, af - absolute frequency

* significant reliability $(p<0.05)$

Classification of ICC: high reliability: > 0.75; moderate reliability: 0.4-0.75; low reliability: $<0.4$ [32] 


\section{HUMAN MOVEMENT}

J.C. Leme et al., Reliability of UP-balance measures

BTml V
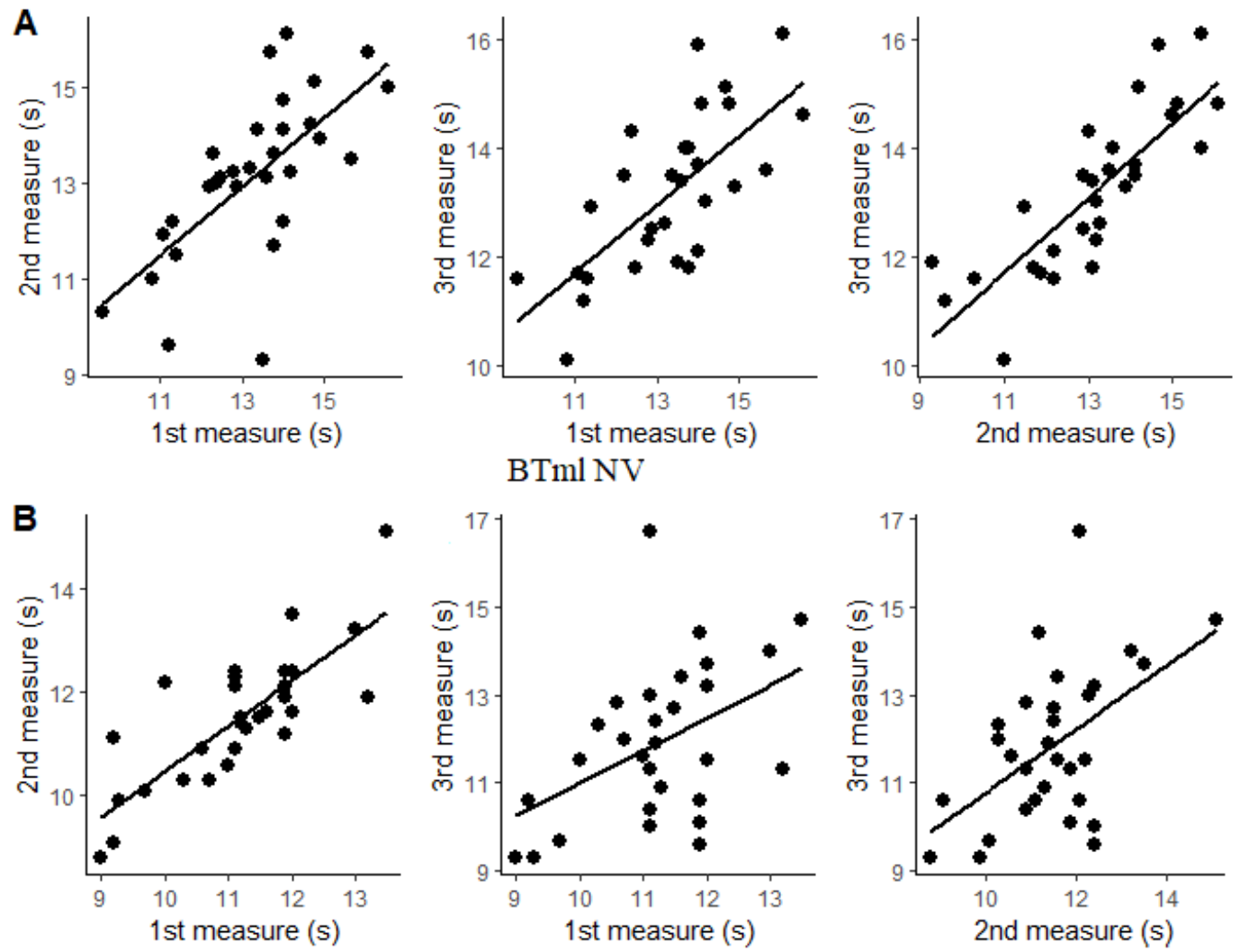

BTml NV
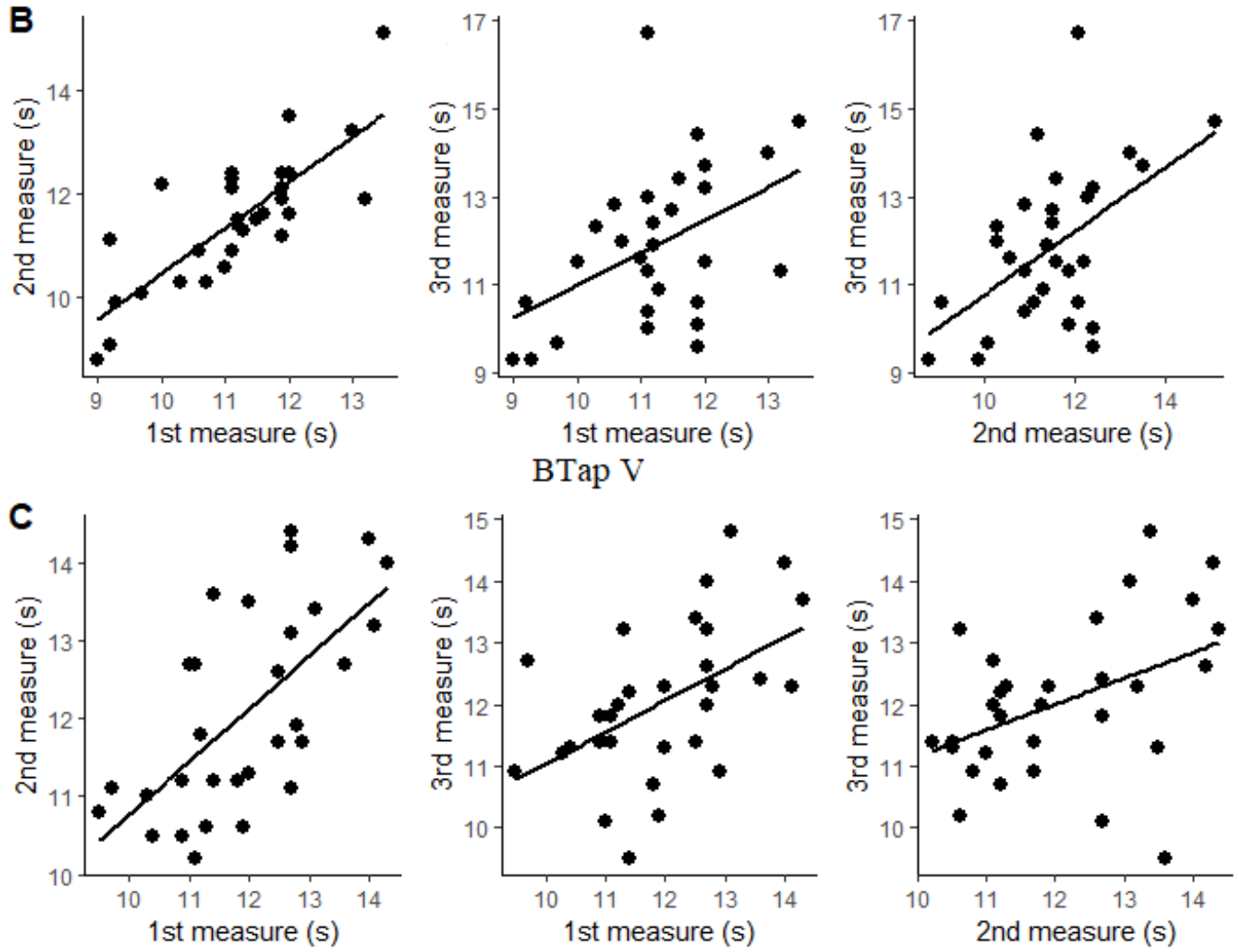

BTap V
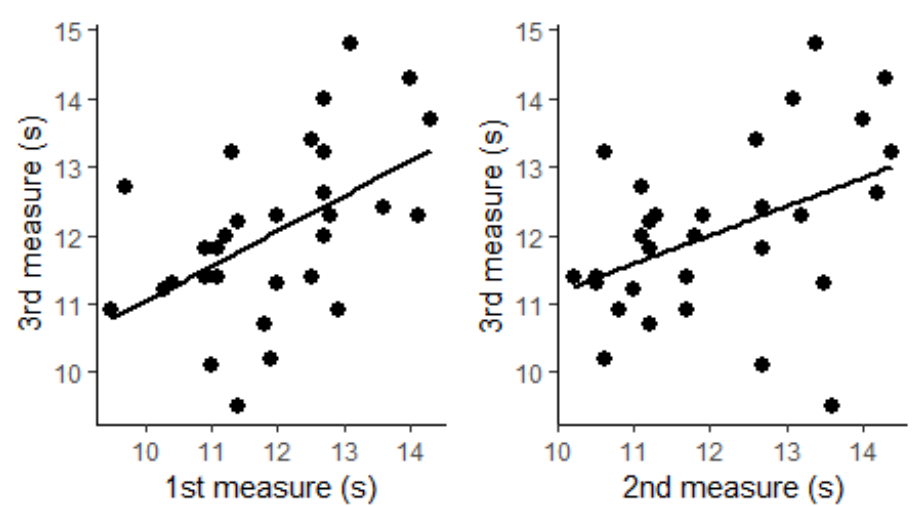

BTap NV
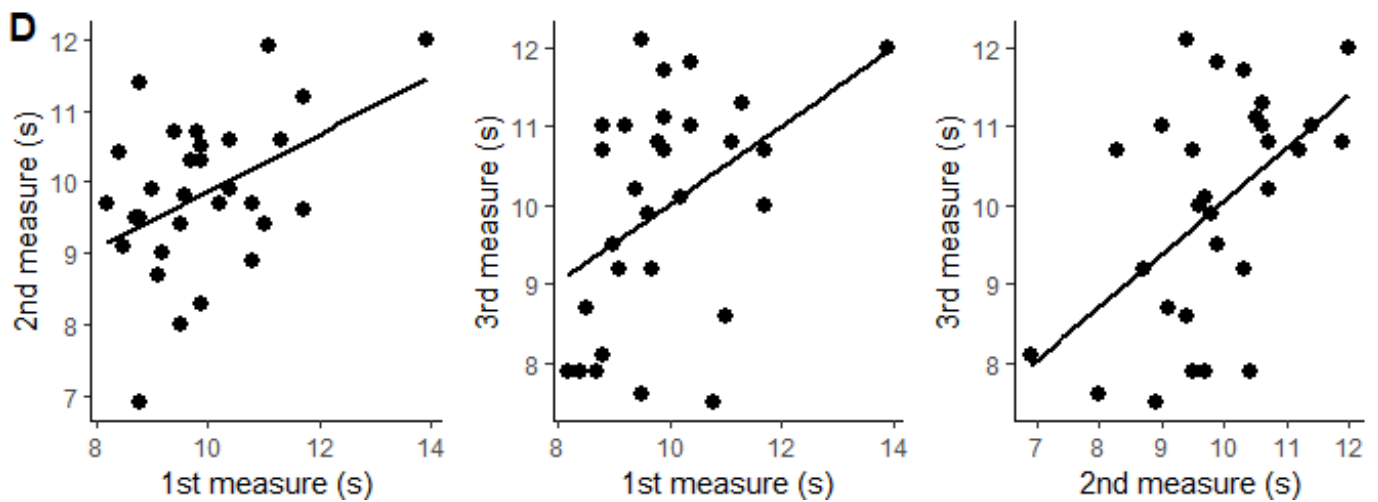

BT - balance time, $\mathrm{ml}$ - medial-lateral direction, ap - anterior-posterior direction, $\mathrm{V}$ - with vision, NV - non-vision

Figure 2. Correlation of the inter-trial measures for the (A) BTml in the V condition, (B) BTml in the NV condition, (C) BTap in the V condition, and (D) BTap in the NV condition 
NTml V
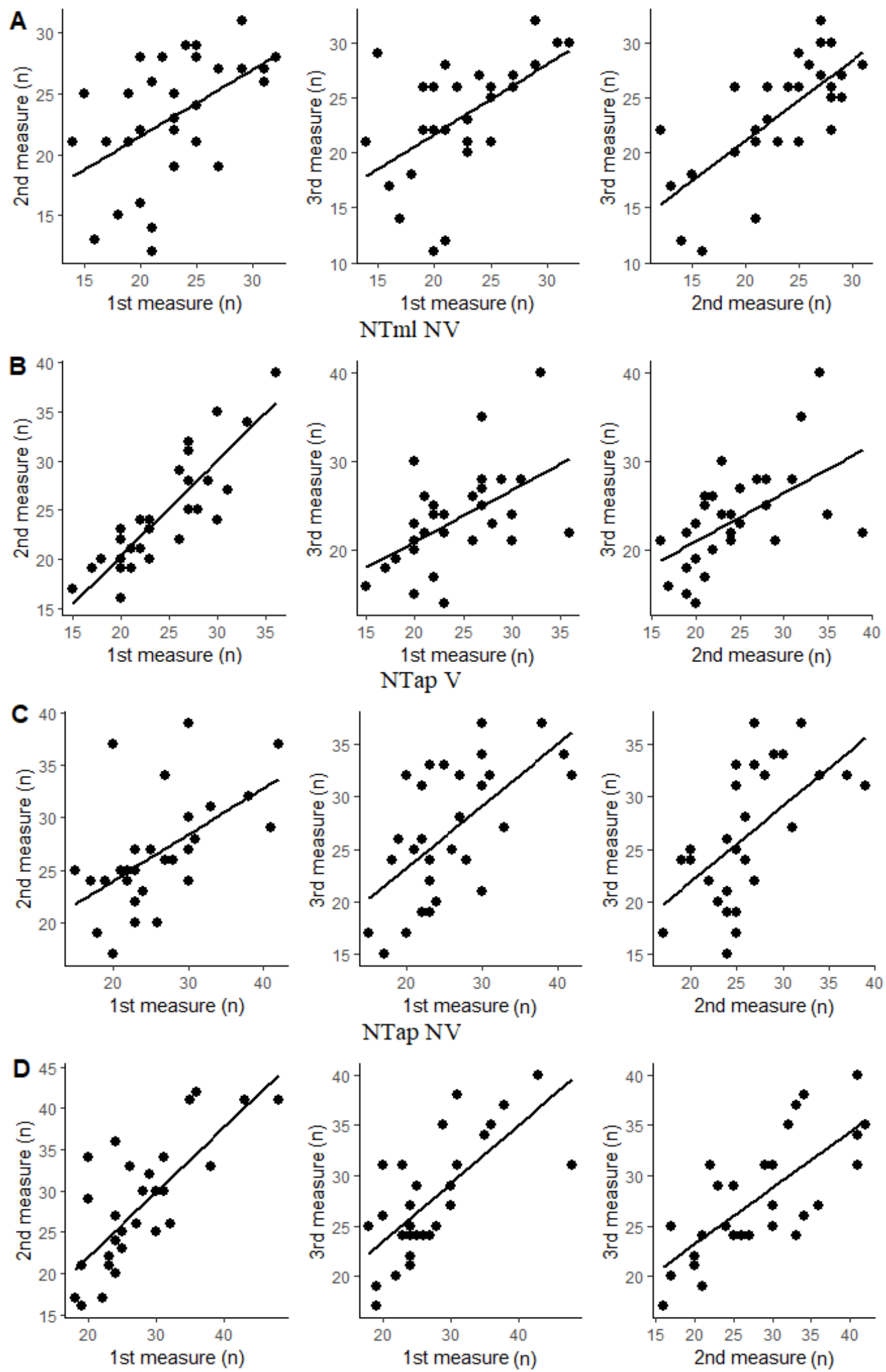

NT - number of touches of the platform border on the ground, $\mathrm{ml}$ - medial-lateral direction, ap - anterior-posterior direction, $\mathrm{V}$ - with vision, NV - non-vision

Figure 3. Correlation of the inter-trial measures for the (A) NTml in the V condition, (B) NTml in the NV condition, (C) NTap in the V condition, and (D) NTap in the NV condition 
as a whole in relation to the environment [36]. Consequently, this could cause less variability between the first and the consecutive attempts in the NV conditions, resulting in greater reliability [34, 35].

The results of the present study indicate low SEM values, and MDC values depicting that UP-balance would be able to determine significant changes in balance task performance. These findings are in line with those of other studies which demonstrated moderateto-high intra-session reliability during dynamic evaluations in young adults $[17,18,22-25]$. A previous study examined the intra-reliability of a developed portable electronic balance measurement system (Clever Balance Board), implying high retest reliability (ICC ranging from 0.90 to 0.96 ) in healthy and physically active young individuals [23].

More recently, another study analysed the reliability of a computerized wobble board and showed fair-toexcellent reliability, with an excellent inter-session reliability during a single-limb test also in young adults [22]. Despite these reliable research results, the constraints characterizing the tasks of balance are different among the instruments. UP-balance provides perturbation (instability) during the whole period of the task. Other instruments are dedicated to more stable situations [17, 18, 22-25, 37]. Therefore, we believe that UP-balance may be a challenging task for balance analysis and training, given the great instability provided, since postural control responses are related to environmental constraints and task demands [38].

The results obtained by this study corroborate previous findings which suggested that instrumented portable unstable platforms could be reliable tools for inexpensive and efficient dynamic balance assessments [22]. From a practical perspective, UP-balance offers reliable, sensitive, and low-cost information on dynamic movement. For example, alterations by $1.45 \mathrm{~s} \mathrm{in} \mathrm{BTml}$ $\mathrm{V}$ and by $1.96 \mathrm{~s}$ in BTml NV can be used to assess and train balance by technicians, health professionals, and researchers.

Despite the meaningful findings of this study, some limitations need to be acknowledged. One of them concerns the sample size, selected for convenience. Another limitation is that the sample was limited to young adults. Therefore, future studies should evaluate the reliability of UP-balance measures also in different populations, such as children, adolescents, elderly people, and pathological cases (with a disorder or injury that can compromise balance). Further studies are suggested to analyse the existing relation of UP-balance with other devices measuring postural control and with functional tests of balance. It is also recommended to propose normative data for the classification of balance across different ages.

\section{Conclusions}

The results showed that the inter-trial measures of UP-balance variables presented high reliability in both visual information conditions (V and NV), except for BTap, which exhibited moderate inter-trial reliability for the NV condition. Therefore, UP-balance seems to be a reliable instrument for the analysis of balance in situations of instability on a base support in adults.

\section{Disclosure statement}

No author has any financial interest or received any financial benefit from this research.

\section{Conflict of interest}

The authors state no conflict of interest.

\section{References}

1. Horak FB, Macpherson JM. Postural orientation and equilibrium. In: Rowell LB, Sheperd JT (eds.), Handbook of physiology. New York: Oxford University Press; 1996; 255-292.

2. Winter DA. Human balance and posture control during standing and walking. Gait Posture. 1995;3(4):193-214; doi: 10.1016/0966-6362(96)82849-9.

3. Chang JO, Levy SS, Seay SW, Goble DJ. An alternative to the balance error scoring system: using a low-cost balance board to improve the validity/reliability of sportsrelated concussion balance testing. Clin J Sport Med. 2014;24(3):256-262; doi:10.1097/JSM.00000000000 00016.

4. Wang S-J, Xu D-Q, Su L-N, Li JX. Effect of long-term exercise training on static postural control in older adults: a cross-sectional study. Res Sports Med. 2020;28(4): 553-562; doi: 10.1080/15438627.2020.1795661.

5. Era P, Heikkinen E, Gause-Nilsson I, Schroll M. Postural balance in elderly people: changes over a five-year follow-up and its predictive value for survival. Aging Clin Exp Res. 2002;14(Suppl. 3):37-46.

6. Era P, Avlund K, Jokela J, Gause-Nilsson I, Heikkinen E, Steen B, et al. Postural balance and self-reported functional ability in 75-year-old men and women: a crossnational comparative study. J Am Geriatr Soc. 1997; 45(1):21-29; doi: 10.1111/j.1532-5415.1997.tb00973.x.

7. Piirtola M, Era P. Force platform measurements as predictors of falls among older people - a review. Gerontology. 2006;52(1):1-16; doi: 10.1159/000089820.

8. Veiga Bruniera CA, Rodacki ALF. Stabilometric responses of young and elderly to recover balance after an unexpected controlled perturbation [in Portuguese]. Rev Educ Fis. 2014;25(3):345-351; doi: 10.4025/reveducfis. v25i3.21495. 
9. Teixeira CS, Paludette Dorneles P, Cuozzo Lemos LF, Pranke GI, Garcia Rossi A, Mota CB. Evaluation the influence sensory stimuli that keep body balance in elderly women [in Portuguese]. Rev Bras Geriatr Gerontol. 2011;14(3):453-460; doi: 10.1590/S1809-982320110 00300006.

10. Corrêa Soares J, Weber P, Trevisan ME, Trevisan CM, Mota CB, Garcia Rossi A. Influence of pain on postural control in women with neck pain [in Portuguese]. Rev Bras Cineantropom Desempenho Hum. 2013;15(3): 371-381; doi: 10.5007/1980-0037.2013v15n3p371.

11. Ko J-H, Newell KM. Aging and the complexity of center of pressure in static and dynamic postural tasks. Neurosci Lett. 2016;610:104-109; doi: 10.1016/j.neulet.2015.10.069.

12. Dos Santos Lima E, de Lima AC, Okazaki VHA, Teixeira LA. Effect of load predictability of manual actions on postural control [in Portuguese]. Rev Bras Cienc Esporte. 2008;29(2):45-56.

13. Mann L, Kleinpaul JF, Teixeira CS, Mota CB. Sensorial systems influence on the maintenance of the balance in pregnant [in Portuguese]. Fisioter Mov. 2011;24(2): 315-325; doi: 10.1590/S0103-51502011000200013.

14. Petró B, Papachatzopoulou A, Kiss RM. Devices and tasks involved in the objective assessment of standing dynamic balancing - a systematic literature review. PLoS One. 2017;12(9):e0185188; doi: 10.1371/journal.pone.0185188.

15. Ringhof S, Stein T. Biomechanical assessment of dynamic balance: specificity of different balance tests. Hum Mov Sci. 2018;58:140-147; doi: 10.1016/j.humov. 2018.02.004.

16. Gribble PA, Hertel J, Plisky P. Using the Star Excursion Balance Test to assess dynamic postural-control deficits and outcomes in lower extremity injury: a literature and systematic review. J Athl Train. 2012;47(3): 339-357; doi: 10.4085/1062-6050-47.3.08.

17. Plisky PJ, Gorman PP, Butler RJ, Kiesel KB, Underwood FB, Elkins B. The reliability of an instrumented device for measuring components of the Star Excursion Balance Test. North Am J Sports Phys Ther. 2009; 4(2):92-99.

18. Shaffer SW, Teyhen DS, Lorenson CL, Warren RL, Koreerat CM, Straseske CA, et al. Y-balance test : a reliability study involving multiple raters. Mil Med. 2013; 178(11):1264-1270; doi: 10.7205/MILMED-D-13-00222.

19. Fusco A, Giancotti GF, Fuchs PX, Wagner H, da Silva RA, Cortis C. Y balance test: are we doing it right? J Sci Med Sport. 2020;23(2):194-199; doi: 10.1016/j.jsams.2019. 09.016.

20. Yaggie JA, Campbell BM. Effects of balance training on selected skills. J Strength Cond Res. 2006;20(2):422428; doi: 10.1519/R-17294.1.

21. Verhagen E, van der Beek A, Twisk J, Bouter L, Bahr R, van Mechelen W. The effect of a proprioceptive balance board training program for the prevention of ankle sprains: a prospective controlled trial. Am J Sports
Med.2004;32(6):1385-1393; doi: 10.1177/036354650 3262177.

22. Fusco A, Giancotti GF, Fuchs PX, Wagner H, Varalda C, Capranica L, et al. Dynamic balance evaluation: reliability and validity of a computerized wobble board. J Strength Cond Res. 2020;34(6):1709-1715; doi: 10.1519/ JSC.0000000000002518.

23. Šarabon N, Mlaker B, Markovic G. A novel tool for the assessment of dynamic balance in healthy individuals. Gait Posture. 2010;31(2):261-264; doi: 10.1016/j.gaitpost.2009.11.001.

24. Lininger MR, Leahy TE, Haug EC, Bowman TG. Testretest reliability of the Limits of Stability test performed by young adults using NeuroCom ${ }^{\circledast}$ VSR Sport. Int J Sports Phys Ther. 2018;13(5):800-807; doi: 10.26603/ ijspt20180800.

25. Naylor ME, Romani WA. Test-retest reliability of three dynamic tests obtained from active females using the NeuroCom Balance Master. J Sport Rehabil. 2006;15(4): 326-337; doi: 10.1123/jsr.15.4.326.

26. Okazaki VHA. Dynamic Balance Task - unstable platform hardware (customized device for the analysis of the dynamic balance in unstable conditions) [in Portuguese]. Available from: https://okazaki.webs.com/ produtostecnolgicos.htm\#297023637.

27. Leme JC, Coelho Candido CR, Okazaki VHA. Effect of visual occlusion and light touch on dynamic postural balance on an unstable platform in elderly and young adult women [in Portuguese]. J Phys Educ. 2018;29(1): e2918; doi: 10.4025/jphyseduc.v29i1.2918.

28. De Oliveira TF, Lopes Vieira JL, Grimble Gonçalves dos Santos AI, Okazaki VHA. Dynamic balance in teenagers with Down syndrome and teenagers with typical development [in Portuguese]. Motriz. 2013;19(2):378390; doi: 10.1590/S1980-65742013000200015.

29. Coelho Candido CR, Secco Faquin B, Okazaki VHA. Analysis of the constrained action hypothesis and the effect of the focus of attention in balance on unstable platform [in Portuguese]. Rev Educ Fis. 2012;23(4): 655-662; doi: 10.4025/reveducfis.v23.4.17036.

30. Castelani RA, de Oliveira TF, Secco Faquin B, Bayeux Dascal J, Marques I, Okazaki VHA. Analysis of dynamic balance in practitioners of classical ballet, of ballroom and non-practitioners of dance [in Portuguese]. Rev Educ Fis. 2014;25(4):597-607; doi: 10.4025/reveducfis.v25i4.22951.

31. Matsudo S, Araújo T, Matsudo V, Andrade D, Andrade E, Oliveira LC, et al. International Physical Activity Questionnaire (IPAQ): study of validity and reliability in Brazil [in Portuguese]. Rev Bras Ativ Fis Saúde. 2001; 6(2):5-18; doi: 10.12820/rbafs.v.6n2p5-18.

32. Fleiss JL. Reliability of measurement. In: Fleiss JL, The design and analysis of clinical experiments. New York: John Wiley \& Sons, Inc.; 1986; 1-32.

33. Koo TK, Li MY. A guideline of selecting and reporting intraclass correlation coefficients for reliability research. J Chiropr Med. 2016;15(2):155-163; doi: 10.1016/j. jcm.2016.02.012. 


\section{HUMAN MOVEMENT}

J.C. Leme et al., Reliability of UP-balance measures

34. Qiu H, Xiong S. Center-of-pressure based postural sway measures: reliability and ability to distinguish between age, fear of falling and fall history. Int J Ind Ergon. 2015;47:37-44; doi: 10.1016/j.ergon.2015.02.004.

35. Bauer C, Gröger I, Rupprecht R, Gaßmann KG. Intrasession reliability of force platform parameters in community-dwelling older adults. Arch Phys Med Rehabil. 2008;89(10):1977-1982; doi: 10.1016/j.apmr.2008.02. 033.

36. Lee DN, Lishman JR. Vision - the most efficient source of proprioceptive, information for balance control. Agressologie. 1977;18(A):83-93.

37. Chen C-L, Lee J-Y, Horng R-F, Lou S-Z, Su F-C. Development of a three-degrees-of-freedom moveable platform for providing postural perturbations. Proc Inst Mech Eng H. 2009;223(1):87-97; doi: 10.1243/0954 4119JEIM482.

38. Chen C-L, Lou S-Z, Wu H-W, Wu S-K, Yeung K-T, Su F-C. Effects of the type and direction of support surface perturbation on postural responses. J Neuroeng Rehabil. 2014;11(1):50; doi: 10.1186/1743-0003-11-50. 